\title{
Impacts of biophilic design on the development of gerotranscendence and the Profile of Mood States during the COVID-19 pandemic
}

\author{
Yasemin Afacan (iD) \\ Department of Interior Architecture \& Environmental Design, Interdisciplinary Neuroscience Program, \\ Bilkent University, TR-06800 Bilkent, Ankara, Turkey \\ Email: yasemine@bilkent.edu.tr
}

(Accepted 19 November 2021)

\begin{abstract}
To live in a good mood is not only a key consideration for future age-friendly communities, but also a critical necessity for positive ageing. Despite growing evidence of correlations between contact with nature and stress reduction, little is known about the effect of nature integration in indoor environments. Thus, this study aimed to answer the following research questions: (a) How do biophilic characteristics of home environments correlate with older adults' experience of the multiple levels of the theory of gerotranscendence? and (b) What is the relationship between these experiences and the mood states of these older adults? The study was based on a comparative analysis to scrutinise the impact of the COVID-19 pandemic on these questions. The data were gathered through questionnaires with 450 older adults aged between 65 and 95 years, and stratified by the biophilic characteristics of their living environments: indoor biophilic, outdoor biophilic and nonbiophilic. Two sets of data were collected with the same participants, respectively, before the COVID-19 pandemic (June to October 2018) and during the COVID-19 pandemic (June to October 2020). It found that the biophilic characteristics of home environments are correlated dynamically with older adults' ageing experience and mood states. The study indicates that outdoor biophilic features facilitate the recovery of tension mood effects of the COVID-19 pandemic, whereas indoor biophilic features facilitate recovery from depression and anger.
\end{abstract}

Keywords: gerotranscendence; Profile of Mood States; biophilic design; COVID-19; age-friendly environments

\section{Introduction}

Ageing studies have been long interested in mood and its relationship with psychological wellbeing. To live in a good mood is not only a key consideration for future age-friendly communities, but also a critical necessity for positive ageing and sustainable development. Mental health and mood states are often mentioned in the

(C) The Author(s), 2021. Published by Cambridge University Press. This is an Open Access article, distributed under the terms of the Creative Commons Attribution licence (http://creativecommons.org/licenses/by/4.0/), which permits unrestricted re-use, distribution and reproduction, provided the original article is properly cited. 
2030 Agenda for Sustainable Development. The 17 Sustainable Development Goals target a transformative agenda focusing on the prevention of disasters, climate change and inequalities that could result in mental illness and negative mood states (Council of Europe, 2021). According to the Mental Health Action Plan 2013-2020 (World Health Organization, 2013), promotion and prevention are key universal objectives to ensure people's health and wellbeing by reducing stress and enhancing environmental sustainability to support the healing process. However, there are still increasing rates of people suffering from negative moods and mental illness. According to the World Health Organization, one in ten people worldwide lives with a mental disorder, whereas approximately one in five people in the United States of America has anxiety and depression (Substance Abuse and Mental Health Services Administration, 2018) and two in five people in Turkey live in a negative mood (Turkstat, 2019).

Although a number of studies have found that older adults may be more motivated to maintain a good mood than younger adults because they remember positive stimuli over negative stimuli (Kunzmann et al., 2000), recent studies report that one's capacity to enhance mood could be limited by cognitive training and participation in physical and social activities (Piccirilli et al., 2019). Accordingly, the effects of physical exercise (Gomes-Osman et al., 2018), cognitive training (Clark et al., 2017), and the psychological and restorative benefits of nature (Kaplan and Kaplan, 1989; Hartig, 2004) have been extensively studied regarding the phenomenological inquiry of becoming, versus being, old. 'If an older person is motivated to adapt in positive ways, then the potential to continue developing and growing into very old age is enhanced' (Washburn and Williams, 2020: 11). Although there is diversity between varied approaches and methodologies across ageing studies, on the macro level they have a common increased understanding of the relevance of person-environment interaction in later life in coping with different aspects of gerotranscendence (Tornstam, 2005, 2011), such as adapting to changes on multiple levels (Calasanti and King, 2021), maintaining independence (Bauger and Bongaardt, 2016) and having an awareness of age-related changes (Diehl and Wahl, 2010).

The current COVID-19 pandemic has made the subjective experience of ageing even more significant across the world. Long-term social distances with reduced interaction cause older adults to experience undue stress, fewer relationships and uncertainties about the future (Lai et al., 2016; Chee, 2020). Existing environmental gerontology studies show the positive effects of spaces and structures on older users. Despite the growing evidence of correlations between nature contact and stress reduction in urban environments (Ulrich et al., 1991; Van den Berg et al., 2007; Jović and Mitić, 2020), little is known about the effect of nature integration in indoor environments (Yin et al., 2020). Long-term direct or indirect connections of humans with nature, called biophilic design, is listed as a key approach in reducing stress and anxiety while increasing positive moods. Although the rules of biophilic environments are straightforward to put in practice (Grinde and Patil, 2009), researchers in design, environmental psychology, environmental gerontology, and public and clinical health are still struggling to translate systematically the understanding and benefits of nature to indoor architecture that go beyond the presence of plants (Salingaros, 2019). Thus, this study aims to answer the following research questions: 
RQ1: How do the biophilic characteristics of home environments correlate with older adults' experience of the multiple levels of the theory of gerotranscendence?

RQ2: What is the relationship between these experiences and the mood states of these older adults?

The following hypotheses are formulated to elaborate these questions in detail:

H1: There is a statistically significant stress level difference between indoor biophilic and non-biophilic environments.

$\mathrm{H} 2$ : All dimension levels of the Gerotranscendence Scale are statistically affected by the COVID-19 pandemic.

H3: The effect of the Gerotranscendence Scale level on the overall mood states significantly depends on the biophilic character of the home environment as the moderator.

H4: The biophilic design positively moderates the relationship between gerotranscendence level and the overall mood states.

The study is based on a comparative analysis to scrutinise the impact of the COVID-19 pandemic on these research questions. It is expected that this comparison study will lead to a more comprehensive understanding of the correlation among subjective ageing, biophilic design and mood states under changing circumstances, such as pandemic conditions.

\section{Multiple levels of the theory of gerotranscendence}

The theory of gerotranscendence was defined as a developmental theory of positive ageing by Tornstam (1989). According to Tornstam (2005), the ageing experience is defined as a new way of life perspective through which oneself, others and activities are seen as more profound, thereby encouraging a cosmic comprehension of life and a positive mood. This comprehension is a shift, as explained by Tornstam (2005), under the two types of transcendence: (a) cosmic transcendence, as a shift from the material to the meta-perspective (reflecting a Zen Buddhist-type approach); and (b) ego transcendence, as a meditation journey to solitude. This theory was developed as a result of conflict between empirical data and theoretical assumptions. Unlike the expected decrease in life satisfaction, there is a developmental context for late life, which is examined in thousands of studies (Patton, 2006; Chen et al., 2019); some of these studies refer to gerotranscendence as a possibility rather than a myth (Jewell and Nell, 2014). Harper (2014) highlighted the significance of gerotranscendence regarding the social and economic implications of the changing patterns of the ageing population. Rodrigues (2016) focused on the value of visual art programmes for older adults in long-term care and concluded that gerotranscendence could be experienced in creative art forms. Tesch-Römer and Wahl (2017) emphasised individual differences in late life and argued that there is an essential need for environmental and societal interventions for successful ageing based on Rowe and Kahn's (2015) model. Jothikaran et al. (2020) conducted a qualitative study to examine the effects of living arrangements on Indian older adults' sense of belonging and the challenges they experience. 
Successful and positive ageing has been discussed in Erikson's psycho-social stages of development as well (Erikson, 1950, 1963, 1982). Erikson's theory, which was built on eight stages (infancy, early childhood, preschool, school age, adolescence, young adulthood, middle adulthood and maturity), emphasises the role of culture and society on an individual's development (Erikson, 1982). According to Erikson's theory, each stage has conflicts that influence experiences to become turning points. Related to positive ageism, the final stage, 'maturity', has conflict with ego and reflection on life as an important event; if it is handled well it can be turned into wisdom. 'As Tornstam himself states, his theory of gerotranscendence can be very closely related to Erikson's final and eighth stage of human psycho-social development' (Ratan and de Vries, 2020: 1399). Ratan and de Vries (2020) investigated longevity and the narratives of centenarians, focusing on the value of Erikson's psycho-social stages of development and Tornstam's theory of gerotranscendence. However, there are still limitations in these two theories. There are debates regarding its operationalisation and generalisability considering different cultural backgrounds (Diehl and Wahl, 2010; Ehni and Wahl, 2020). The challenges and concerns associated with gerotranscendence are complex, and there are many other studies in the ageing literature addressing these issues in physiological, psychological, social, emotional and spiritual dimensions. Therefore, contrary to the many studies reviewing and conceptualising all these dimensions, the reflectance of gerotranscendence within the framework of this study lies in its architectural portrayal that could influence the mood of older adults. Moreover, the theoretical perspective of gerotranscendence also aligns with the biophilic design approach.

\section{Biophilic design and its healing influence on users}

Biophilic design emerged from the theory of biophilia, a Greek word meaning 'love of life'. It sees humans as a part of nature and considers their evolvement with nature in psychological, emotional and spiritual manners (Wilson, 1984). Due to increased urbanisation, there is less access to natural environments and a higher ratio of time spent indoors (Neil et al., 2001). In coping with these urbanisation challenges, biophilic design becomes more important than ever to reduce stress and enhance performance, creativity and wellbeing (Kellert and Wilson, 1993). A review of the design literature shows that there are well-defined biophilic guidelines, strategies and attributes to practise nature in built environments and understand opportunities for relating humanity to nature in buildings. Although the metrics in these strategies differ slightly, the aim is the same. Kellert et al. (2008) proposed more than 70 different strategies to incorporate biophilia that go beyond greening buildings and reflecting the ecological design process. These strategies are summarised under the following six elements: (a) environmental features, such as water, air, sunlight; (b) natural shapes, such as egg, botanical motifs, shells; (c) natural patterns and process, such as fractals, growth; (d) light and space, such as light pools, natural light; (e) place-based relationships, such as landscape ecology; and (f) evolved human-nature relationships, such as curiosity, change, order. Heerwagen and Gregory (2011) contextualised these strategies under the following seven attributes of biophilic design: sensory richness, motion, serendipity, 
variations on a theme, resilience, sense of freeness and prospect, and refuge. These seven attributes aim to combine sustainability, focusing mainly on lowering environmental impact, with the positive experience of nature. Later, Browning et al. (2014) proposed the biological connection of humans with nature under the three major categories of biophilic design. The first category includes the seven guidelines of integrating nature in the space patterns. These guidelines are: visual connection with nature, non-visual connection with nature, non-rhythmic sensory stimuli, thermal and airflow variability, presence of water, dynamic and diffused light, and connection with natural systems. These seven guidelines focus the direct and physical presence of nature in built environments. The second category is natural analogues patterns, defined under the three principles of biomorphic forms, material connection, and complexity and order. They are in the form of indirect experiences of nature, such as colour, material, shapes, etc. The last category is defined as nature of space patterns, which addresses the spatial configurations of space under the four principles: prospect, refuge, mystery and risk. Researchers studied each of these 14 patterns regarding their capability to support stress reduction, improve cognitive performance and to enhance mood states. To exemplify, the first guideline of the first strategy, visual connection with nature, helps reduce stress by lowering blood pressure and heart rate (Brown et al., 2013) while improving concentration and attention (Vessel and Biederman, 2006) and enhancing overall happiness (Barton and Pretty, 2010)

Recent studies have supported a quantitative approach to explore interventions of biophilic design and optimise its implementation strategies (Berto, 2014). The researchers of the above-mentioned guidelines did not propose to assess the measures of these guidelines in a quantitative manner. However, Salingaros (2019) suggested quantifying biophilic design by calculating the 'biophilic index' of a building. Table 1 lists the ten components of the biophilic index along with its definitions and the metric used in assessing the index value based on the study by Salingaros (2006). This quantitative approach suggests a numerical estimate that is calculated based on the intensity and presence of each component. Biophilic index (represented by $B$ ) could range from 0 to 20 depending on the building characteristics. Although having a maximum biophilic index score of $B=20$ could not be expected, increasing the index value depends on various practical and theoretical combinations of these ten components (Salingaros, 2015).

It should be noted that this quantitative formulation is not a rigid definition. Still, researchers are searching for answers as to the most important components that influence biophilic effect. To the best of our knowledge, there are no studies that analyse the biophilic index of environments associated with gerotranscendence in extreme conditions, such as a pandemic. There is only one study investigating biophilic design in extreme climates (Parsaee et al., 2019). These ten biophilic components have strong associations with emotional and physiological factors that require considering multiple interacting variables (Salingaros, 2019).

\section{A review of the mood studies and the Profile of Mood States (POMS)}

Mood is defined as a positive or negative emotional state of changing intensity as a response to life circumstances. The variability in mood states is a key determinant 
Table 1. The ten components of the biophilic index adapted from Salingaros (2006)

\begin{tabular}{|c|c|}
\hline Components & Definitions \\
\hline Sunlight & $\begin{array}{l}\text { Considering directions and varying intensities of daylight, shade and } \\
\text { shadow (Kellert et al., 2008) }\end{array}$ \\
\hline Colour & $\begin{array}{l}\text { Using a wide variety of hues, chroma and values of natural } \\
\text { environments, such as earth tones, shades of an overcast sky } \\
\text { (Heerwagen and Gregory, 2011) }\end{array}$ \\
\hline Gravity & $\begin{array}{l}\text { Producing a creative balance that transforms the equilibrium of nature } \\
\text { to buildings vertically (Browning et al., 2014) }\end{array}$ \\
\hline Fractals & $\begin{array}{l}\text { Integrating repetition in variations of nature patterns, such as varying } \\
\text { patterns of a snowflake or leaves (Kellert et al., 2008) }\end{array}$ \\
\hline Curves & $\begin{array}{l}\text { Integrating organic forms of nature literally, structurally or } \\
\text { metaphorically, such as shell-like structures, or egg-like or tubular } \\
\text { forms (Kellert and Wilson, 1993) }\end{array}$ \\
\hline Detail & $\begin{array}{l}\text { Reflecting the cognitive richness of nature stimulating creativity, } \\
\text { curiosity, discovery, etc. (Kellert et al., 2008) }\end{array}$ \\
\hline Water & $\begin{array}{l}\text { Considering its visual and audible presence, which stimulates higher } \\
\text { levels of human liking and preference (Kellert and Wilson, 1993) }\end{array}$ \\
\hline Life & $\begin{array}{l}\text { Inserting directly or indirectly living plants or animals in a literal, } \\
\text { structural or metaphorical manner (Heerwagen and Gregory, 2011) }\end{array}$ \\
\hline $\begin{array}{l}\text { Representations of } \\
\text { nature }\end{array}$ & $\begin{array}{l}\text { Simulating natural features such as structure, planning, façade design, } \\
\text { decoration, ornamentation, etc. (Kellert and Wilson, 1993) }\end{array}$ \\
\hline Organised complexity & $\begin{array}{l}\text { Addressing richness of structure and organisation in the form of spatial } \\
\text { hierarchy, variety, controlled variety (Kellert et al., 2008) }\end{array}$ \\
\hline Equation & $\begin{array}{l}\text { Estimates: none }=0 \text {, some }=1 \text {, a large amount }=2 \text {. } \\
\text { Biophilic index } B=\text { Light }+ \text { Colour }+ \text { Gravity }+ \text { Fractals }+ \text { Curves }+ \text { Detail + } \\
\text { Water }+ \text { Life }+ \text { Representations of nature }+ \text { Organised complexity. } \\
\text { Range: } 0<B<20 \text {. }\end{array}$ \\
\hline
\end{tabular}

of psychological wellbeing outcome (Jin, 1992). There is extensive literature on measuring mood, which is systematised under depression, anxiety and multiple moodmeasuring studies. Depressed mood is measured most commonly by the following measures: the Zung Self-rating Depression Scale (Zung, 1965), used for affective, psychological and somatic symptoms; the 20-item Center for Epidemiologic Studies Depression Scale (CES-D; Radloff, 1977), designed for community populations; and the Geriatric Depression Scale (GDS; Yesavage et al., 1983), designed for clinical populations. Anxiety is measured most commonly by the State Trait Anxiety Inventory (STAI; Spielberger, 1983), which is designed for current and general anxiety. With regards to multiple mood-measuring studies, the Positive and Negative Affect Schedule (PANAS; Watson et al., 1988) is the most popular 20-item scale used for self-reporting mood over a week. The Global Mood Scale (GMS; Denollet, 1993) is another commonly used scale for measuring these two moods but differs from PANAS by defining the negative affect as exhaustion. There are also dementia-specific mood scales, such as the Dementia Mood Assessment Scale (DMAS; Sunderland et al., 1988), which measures observable mood while rating functional abilities, and The Cornell Scale for Depression in Dementia (CSDD; 
Alexopoulos et al., 1988), which is designed to assess depressive symptoms of participants with dementia.

These self-reported measures are critical when assessing mood in older adults due to the difficulties of data collection, such as time, impracticality of computerised applications and cognitive decline (Dennis et al., 1995). POMS (McNair et al., 1971) is defined as one of the most efficient self-report assessment tools that could be valid for current mood states; it is conducted in many different studies with alternate language forms (Watson, 2000). POMS is a 65-item affect rating tool which uses a five-point ordinal scale $(0=$ not at all, $4=$ extremely) to identify personality under the six mood states: five for negative mood (tension/anxiety (TA), depression/dejection (DD), anger/hostility (AH), fatigue/inertia (FI) and confusion/bewilderment (CB)) and one for positive mood (vigour/activity (VA)). A score for each state is calculated by the sum of the responses for each adjective item defining that state, and an overall mood state score (OM) is obtained by subtracting the sum of the five negative states from the positive state: TA + DD + AH + $\mathrm{FI}+\mathrm{CB}-\mathrm{VA}=\mathrm{OM}$ (McNair et al., 1971). There are several versions of POMS, such as POMS-2nd edition with an additional state of friendliness (FR) (Heucert and McNair, 2012). According to Brown et al. (1995), the shortened version of POMS is the most reliable, valid and proper instrument to measure the mood states of older adults living in community dwellings. In the shortened version of POMS, its 65 items are reduced to 37 items while keeping the internal consistency and reliability of the survey and decreasing the required time it takes to conduct it (Shacham, 1983). Considering the proposed validity and reliability, the present study administered this shortened version to assess the moods of older adults, which is comprehensively explained in the next section.

\section{Methods}

\section{Procedure}

The study was based on two sets of data that were collected with the same participants before the COVID-19 pandemic (between June and October 2018) and during the COVID-19 pandemic (between June and October 2020), respectively. Each dataset was comprised of two questionnaires: the 37-item shortened version of POMS (SV-POMS) and the ten-item Gerotranscendence Scale (GS). The detailed description of these psychological measures used in the study is given in the 'Measures' sub-section. During the first visit, all measures were administered by trained research interviewers to participants during a single session lasting 45-60 minutes. The same questions - although, with random ordering - were conducted during the second visit, considering the role of the biophilic character of home environments on participants' moods during the COVID-19 pandemic. The second visit was also a single session and lasted 75-90 minutes. The reason that the second visit lasted longer than the first visit was due to the COVID-19 transmission and protective measures during the visit, such as wearing masks, avoiding close contact and social distancing, etc. Both visits occurred during similar times of the day to eliminate the potential effect of circadian rhythm on psychological performance. Ethical permission for the study was obtained first by the Ankara Governorship and then later by the Bilkent University Institutional Ethical Review Board. 
Table 2. Socio-demographic characteristics of the participants

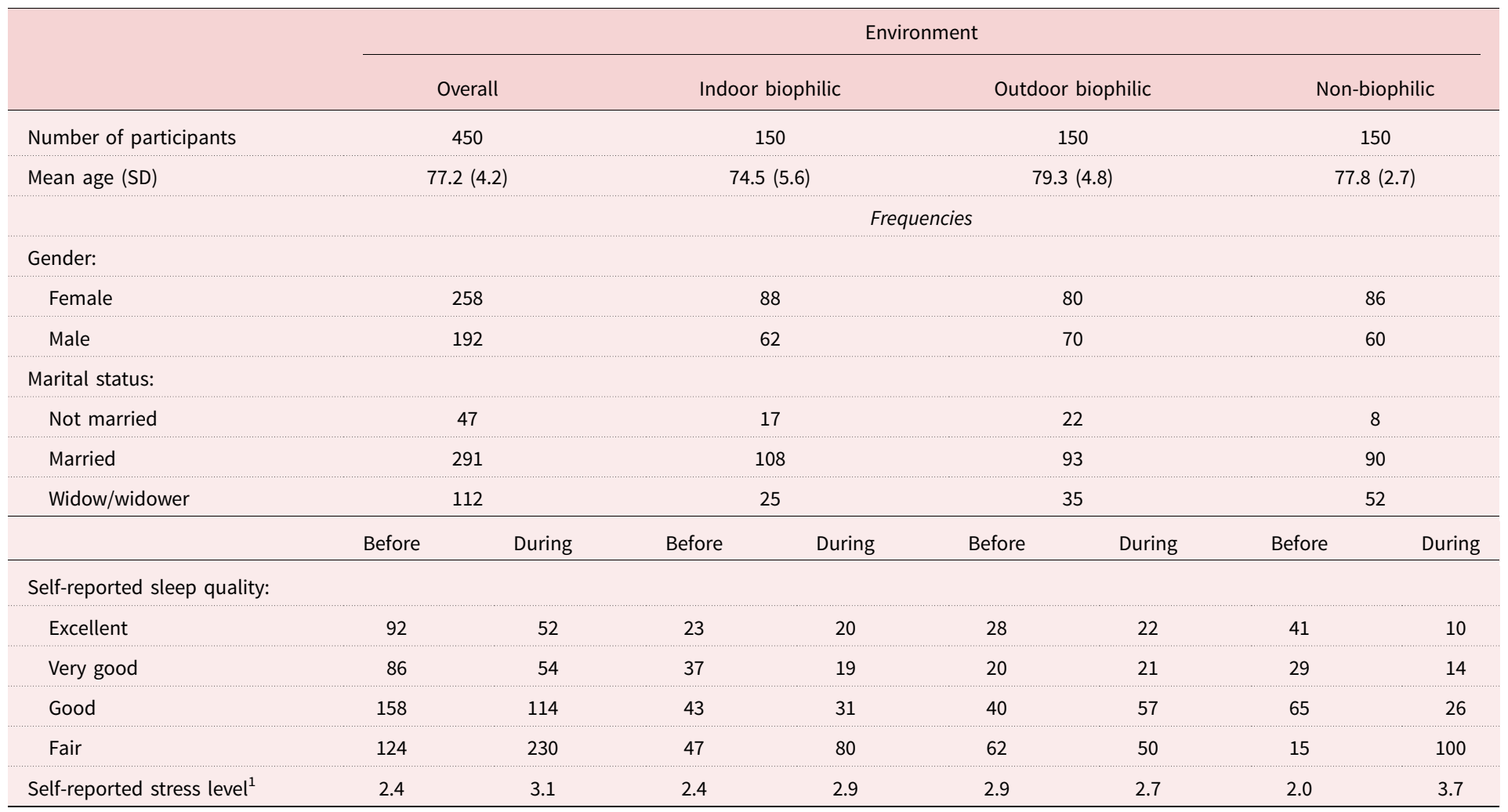

Notes: SD: standard deviation. Before: before COVID-19. During: during COVID-19. $1.1=$ lowest, $5=$ highest. 


\section{Participants}

In the study, a total of 450 older adults aged between 65 and 95 years (mean $=77.2$, standard deviation $=4.2$ ) were recruited among apartment-type clusters of similar urban neighbourhoods in Ankara, Turkey. The overall socio-demographic characteristics of the participants are given in Table 2; 258 participants were female and 192 were male. Most of them (291 participants) were married, whereas 47 participants were unmarried. More than half of the participants ( 86 participants) reported a very good or a good sleep quality (158 participants) before the pandemic. There were no significant differences of demographic characteristics among the groups $(p=0.000)$. However, during the COVID-19 pandemic, there was a significant decrease in the self-reported sleep quality of the participants; half reported a fair sleep quality in the repeated session of the instruments. There were statistically significant differences among the sample groups regarding self-reported sleep quality before and during the pandemic conditions $(p=0.000)$. Non-biophilic living environments were significantly associated with a decrease in self-reported sleep quality. With regards to the biophilic character of living environments, a drastic increase in the number of participants was observed in non-biophilic environments as well as in indoor biophilic environments. Although participants living in outdoor biophilic environments had the highest average mean age, their self-reported sleep quality and stress level remained almost unaffected by the pandemic situation.

There were two criteria when choosing appropriate participants for the study. First, participants were selected among older residents with an average residing length of five years or more to ensure their representation of experience within their home environments. Second, a stratified sample method was used to select apartment-type clusters of similar urban neighbourhoods. The five volunteer architects with 15 years' experience on sustainability projects in various typologies evaluated the residential buildings in these neighbourhoods and identified apartments with a similar floor area (ranging from 120 to 140 square metres) through the Ankara Municipality database. There were three strata of 150 participants each with medium-income level. The first and second strata were formed based on the three categories of biophilic design (Browning et al., 2014), which were categorised as indoor biophilic and outdoor biophilic, respectively. In this study, indoor biophilic was defined as interiors having biophilic features. These features were frequently used in interior design practice, such as double-height ceilings resulting in mezzanine floors that enable enhanced visual and spatial experiences or the use of natural materials (wood and stone) or natural colours (earth-tone and green). Outdoor biophilic was defined as intergrating nature in the outdoor patterns, such as having direct access to a garden or integrating curvilinear lines in façades or the interior circulation patterns of living environments. The biophilic index value of each participant's home was also calculated. This index value in the indoor biophilic stratum ranged from 10.2 to 13.3 ; similarly, the value in the outdoor biophilic stratum was calculated between 10.9 and 13.8. The third stratum includes older adults living in traditional apartments without any biophilic features. The impact factor of each biophilic attribute on the physiological and cognitive performance of older adults has been studied and evaluated in previous research, however, this study presents a multi-sample approach to explore the correlations 
among sampling clusters and ageing experience with and without the COVID-19 pandemic. All of the participants were independent in their daily living activities according to the Barthel Index (Mahoney and Barthel, 1965) and were recorded as mentally healthy in their registered Family Health Centres.

\section{Measures}

The study used two psychological measures. The first measure was the SV-POMS, a widely used affect rating tool with a high internal consistency. Shacham (1983) reduced the 65 items of POMS to 37 items and found the correlation coefficient between short and original scales to be 0.95 . The study used the original SV-POMS, which was composed of the following six sub-scales: tension/anxiety (six items), depression/dejection (eight items), anger/hostility (seven items), vigour/activity (six items), fatigue/inertia (five items) and confusion/bewilderment (five items). SV-POMS with these six sub-scales was prepared based on the Selvi et al. (2011) study that translated the English version to Turkish by an expert team approach. Participants rated the extent to which they were experiencing or had experienced these 37 mood states in the past week. Their responses were based on a five-point scale ranging from 'not at all' (0) to 'extremely' (4). The second measure was the ten-item GS, which was developed by Tornstam (1997). There were two scales of gerotranscendence: GS Type-1 (Tornstam, 1994) including cosmic transcendence (six items) and ego transcendence (four items), and GS Type-2 (Tornstam, 1997) including cosmic transcendence (five items), coherence (two items) and solitude (three items). The study used the GS Type-2 scale, in which time, space and objects reflected the content of cosmic transcendence (see the online supplementary material). The coherence was derived from ego integrity, and the solitude was referred by importance of relations and increased need for allowing reflection and mediation of inner life. Participants rated the extent to how well they agree with each item considering their own personal ageing experiences. These dimensions were measured on a five-point scale ranging from 'not at all' (0) to 'extremely' (4). The responses were scored from 0 to 40 . The high score of the scale represented a high level of gerotranscendence. It is worth noting that unlike the SV-POMS scale, the GS was only translated from English into Turkish for the purpose of this study, and its Turkish version had no previous psychometric studies.

\section{Data-analysing strategy}

The data were analysed statistically using $\mathrm{IBM}^{\circledR} \mathrm{SPSS}^{\circledR}$ Statistics 19 . Analysis of variance (ANOVA) was conducted to test the effectiveness of biophilic design on mood states and ageing experience. Wilcoxon rank-sum was used to determine the significance of differences of mood states among indoor biophilic, outdoor biophilic and non-biophilic samples, considering the COVID-19 pandemic as an observed variable. The statistical difference between non-biophilic and biophilic living environments by the COVID-19 pandemic based on the experience of gerotranscendence was evaluated using one-sample $t$-tests. Chi-square tests were performed to explore the effect of each biophilic category on the relationships between mood state and 
ageing experience. The study also included moderation analysis as a comprehensive statistical method to strengthen the findings. The moderation analysis was analysed statistically using JSAP version 0.14 , which is an open-source, flexible and reliable statistics program developed by University of Amsterdam (JASP, 2021). The study recognised the common method bias, which is defined as a potential problem in the literature of applied research. This occurred when data were collected by the same method, such as Likert-type scales (Podsakoff and Organ, 1986). This study applied the following procedures to reduce the risk of common method bias: applying random ordering of questions, requesting participants to respond to the self-report measures more accurately, avoiding ambiguous items and keeping the items concise while translating them into Turkish. The confidence interval for the statistical tests is defined as 95 per cent.

\section{Results}

\section{Correlations among older adults' gerotranscendence experience and biophilic environments}

The average mean score stress level of the participants was calculated as 2.4. The ANOVA results show that there was a statistically significant difference in the selfreported stress level among the sample groups $(p=0.000)$. The participants living in non-biophilic environments reported the highest stress level with an average mean value of 3.7 during the pandemic, although they reported lower stress levels before the pandemic. The results from the $t$-tests and Wilcoxon rank tests indicate that the participants living both in indoor and non-biophilic environments showed a significantly different pattern regarding self-reported sleep quality and stress level. Their sleep quality decreased while the stress level increased significantly during the COVID-19 pandemic. Hypothesis H1 was supported.

Table 3 shows that there are no significant differences in the overall mean values of cosmic and solitude items considering the repeated measures among the groups ( $p=0.571 ; p=0.000 ; p=0.387$, respectively). The study also used $t$-tests to compare the differences of gerotranscendence experience within the same sample group between two points of time: before the COVID-19 pandemic and during the COVID-19 pandemic (Table 3). With regards to the overall cosmic aspect, only the indoor biophilic sample group shows a statistically significant difference in terms of GS rating, whereas the outdoor biophilic group rated eight of the ten items very similarly. Figure 1 summarises the changes in the GS rating among the three groups in the form of a contour diagram. This diagram confirms the statistical findings and demonstrates that the coherence and solitude aspects were the only dimensions of the GS affected by the pandemic, independent of the designed environment. Hypothesis $\mathrm{H} 2$ was not supported.

\section{Correlations among the POMS scales of older adults in indoor biophilic, outdoor biophilic and non-biophilic environments}

The Cronbach's alpha values for the POMS' six sub-scales were calculated for the sample groups (Table 4). The alpha value, including the two repeated sessions, ranges from 0.98 to 0.88 in indoor biophilic environments; the range for outdoor 
Table 3. The overall mean values of the Gerotranscendence Scale sub-scales

\begin{tabular}{|c|c|c|c|c|c|c|c|c|c|}
\hline & $p$ & \multicolumn{8}{|c|}{ Environment } \\
\hline Cosmic & 0.571 & 1.97 & 1.79 & 2.03 & 1.71 & 2.25 & 2.23 & 1.63 & 1.43 \\
\hline Coherence & 0.000 & 2.50 & 3.01 & 2.43 & 3.06 & 2.56 & 3.21 & 2.66 & 2.30 \\
\hline
\end{tabular}

Notes: Before: before COVID-19. During: during COVID-19. 
(a)
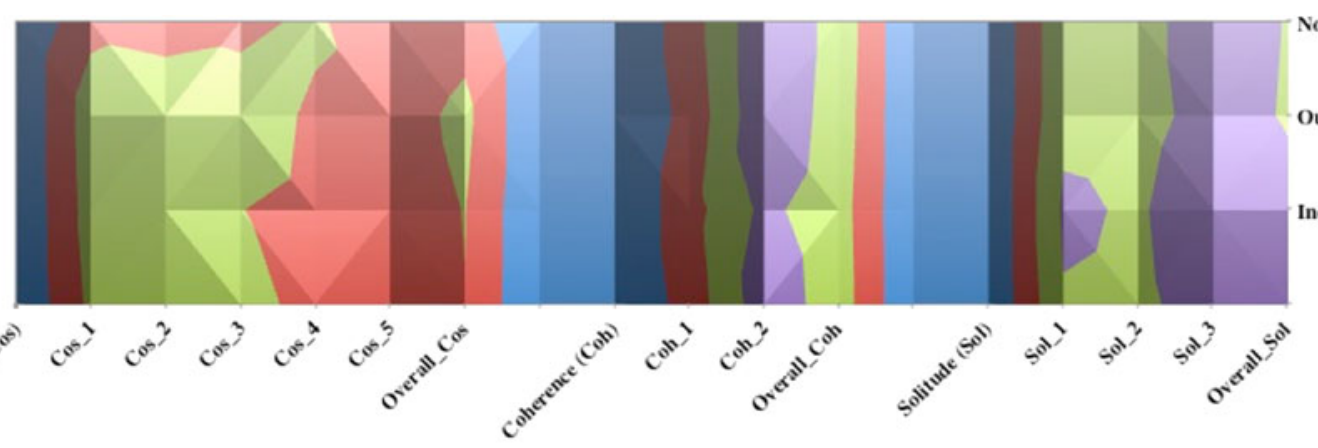

on-biophilic

Outdoor Biophilic $=3-4$

Indoor Biophilic $\quad$ "2-3

$=1 \cdot 2$
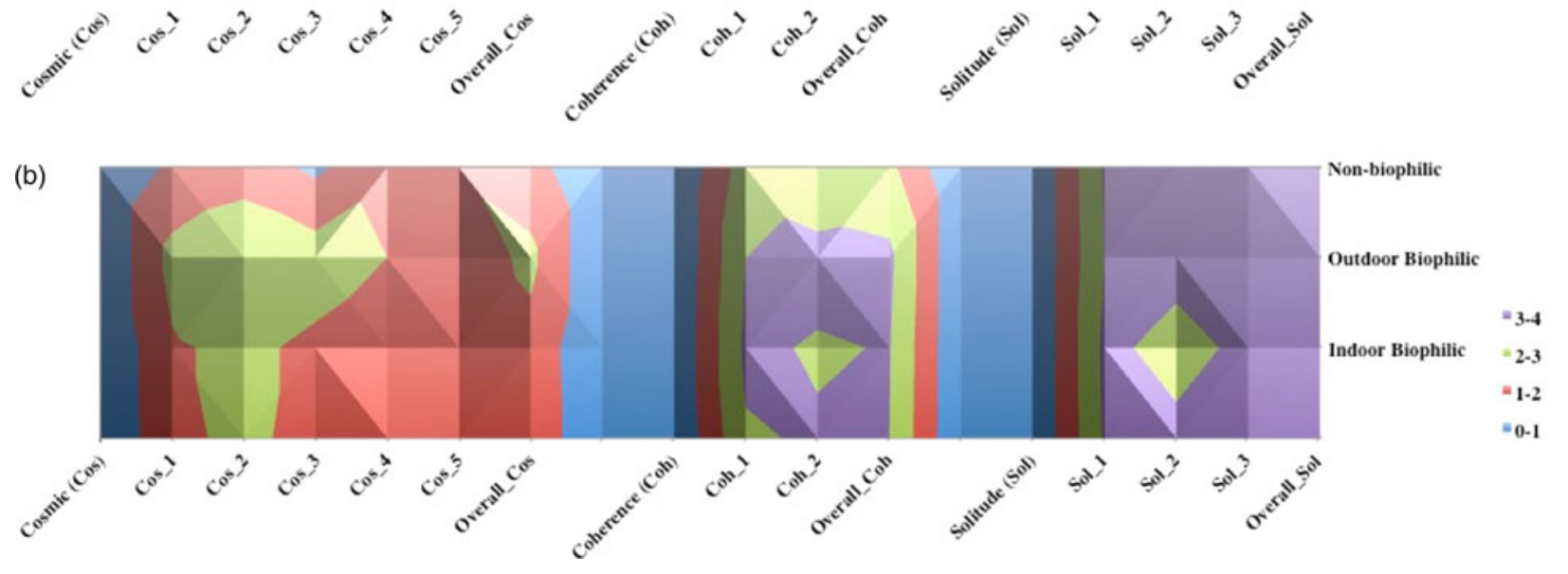

Figure 1. The Gerotranscendence Scale rating among the three groups in the form of contour diagrams: (a) before the COVID-19 pandemic and (b) during the COVID-19 pandemic. 
Table 4. The Cronbach's alpha values for the six sub-scales of the Profile of Mood States

\begin{tabular}{|c|c|c|c|c|c|c|}
\hline & \multicolumn{6}{|c|}{ Environment } \\
\hline & \multicolumn{2}{|c|}{ Indoor biophilic } & \multicolumn{2}{|c|}{ Outdoor biophilic } & \multicolumn{2}{|c|}{ Non-biophilic } \\
\hline & Before & During & Before & During & Before & During \\
\hline Tension/anxiety & 0.98 & 0.92 & 0.84 & 0.95 & 0.87 & 0.89 \\
\hline Depression/dejection & 0.92 & 0.91 & 0.95 & 0.96 & 0.88 & 0.98 \\
\hline Anger/hostility & 0.91 & 0.88 & 0.89 & 0.93 & 0.93 & 0.92 \\
\hline Fatigue/inertia & 0.94 & 0.95 & 0.92 & 0.90 & 0.98 & 0.96 \\
\hline $\begin{array}{l}\text { Confusion/ } \\
\text { bewilderment }\end{array}$ & 0.88 & 0.82 & 0.93 & 0.91 & 0.91 & 0.92 \\
\hline Vigour/activity & 0.91 & 0.97 & 0.91 & 0.95 & 0.90 & 0.93 \\
\hline Overall & 0.93 & 0.94 & 0.97 & 0.98 & 0.96 & 0.92 \\
\hline
\end{tabular}

Notes: Before: before COVID-19. During: during COVID-19.

biophilic environments was $0.84-0.98$, and $0.87-0.98$ for non-biophilic environments. In line with the literature (McNair et al., 1971), this study found lower alpha values for the confusion sub-scale. The study also calculated the mean values of each sub-scale (Table 5). 'Fatigued' was the only item with the highest mean value in all the sample groups with and without the COVID-19 pandemic. 'Confused' was the item with the second highest mean value in all the sample groups in the pandemic condition only. As anticipated, the COVID-19 pandemic revealed a significant change in the overall mood state score. In the non-biophilic environment, the overall mood state score changed from 0.89 to 1.22 , in the indoor biophilic from 0.45 to 0.85 , and in the outdoor biophilic from 0.32 to 0.55 . The results from the Wilcoxon rank tests indicate that the tension and depression mood states of the participants living in non-biophilic environments increased significantly while experiencing the COVID-19 pandemic. The older adults living in the non-biophilic environment, whose GS ratings were affected more by the pandemic, had the highest overall mood state score during the COVID-19 pandemic. The between-participants analyses of the ANOVA results confirm a different pattern in older adults living in non-biophilic environments (Table 5). This sample group shows significant differences in fatigue and tension, whereas the older adults living in indoor and outdoor biophilic environments show identical patterns of differences before the pandemic and during the pandemic.

Table 6 shows correlations among the POMS scales of older adults in indoor biophilic, outdoor biophilic and non-biophilic environments. Compared to indoor biophilic environments, the highest negative correlation was calculated between the activity and tension mood aspects in outdoor biophilic environments, followed by high correlations between depression and tension mood aspects, and between activity and depression mood aspects in the same environment. These correlations are in line with the literature, because outdoor green space exposures, rather than indoor biophilic environments, are more highly linked with decreased depression and 
Table 5. The mean values of each sub-scale of the Profile of Mood States

\begin{tabular}{|c|c|c|c|c|c|c|c|c|}
\hline & \multicolumn{8}{|c|}{ Environment } \\
\hline & \multicolumn{4}{|c|}{ Before COVID-19 } & \multicolumn{4}{|c|}{ During COVID-19 } \\
\hline & Indoor biophilic & Outdoor biophilic & Non-biophilic & $p$ & Indoor biophilic & Outdoor biophilic & Non-biophilic & $p$ \\
\hline Tension/anxiety & 0.71 & 0.58 & 1.60 & 0.001 & 1.18 & 0.88 & 2.17 & 0.000 \\
\hline Depression/dejection & 0.78 & 0.68 & 1.10 & 0.000 & 0.98 & 0.92 & 1.85 & 0.000 \\
\hline Anger/hostility & 0.88 & 0.65 & 0.85 & 0.000 & 1.15 & 0.79 & 0.96 & 0.000 \\
\hline Fatigue/inertia & 0.99 & 10.1 & 2.10 & 0.003 & 1.23 & 1.33 & 2.25 & 0.001 \\
\hline Confusion/bewilderment & 0.45 & 0.51 & 0.59 & 0.001 & 1.14 & 1.28 & 1.33 & 0.002 \\
\hline Vigour/activity & -1.1 & -1.6 & -0.85 & 0.000 & -0.55 & -1.92 & -1.2 & 0.000 \\
\hline Overall mood state & 0.45 & 0.32 & 0.89 & 0.005 & 0.85 & 0.55 & 10.22 & 0.000 \\
\hline
\end{tabular}


Table 6. The correlations among the sub-scales of the Profile of Mood States of older adults in indoor biophilic, outdoor biophilic and non-biophilic environments

\begin{tabular}{|c|c|c|c|c|c|c|}
\hline & $\mathrm{TA}$ & $\mathrm{DD}$ & $\mathrm{AH}$ & $\mathrm{FI}$ & $\mathrm{CB}$ & VA \\
\hline \multicolumn{7}{|l|}{ Tension/anxiety (TA): } \\
\hline Indoor biophilic & 1.0 & & & & & \\
\hline Outdoor biophilic & 1.0 & & & & & \\
\hline Non-biophilic & 1.0 & & & & & \\
\hline \multicolumn{7}{|c|}{ Depression/dejection (DD): } \\
\hline Indoor biophilic & 0.552 & 1.0 & & & & \\
\hline Outdoor biophilic & 0.410 & 1.0 & & & & \\
\hline Non-biophilic & -0.850 & 1.0 & & & & \\
\hline \multicolumn{7}{|l|}{ Anger/hostility $(\mathrm{AH})$ : } \\
\hline Indoor biophilic & 0.330 & 0.489 & 1.0 & & & \\
\hline Outdoor biophilic & 0.415 & 0.312 & 1.0 & & & \\
\hline Non-biophilic & 0.289 & 0.855 & 1.0 & & & \\
\hline \multicolumn{7}{|l|}{ Fatigue/inertia (FI): } \\
\hline Indoor biophilic & 0.369 & 0.423 & 0.299 & 1.0 & & \\
\hline Outdoor biophilic & 0.252 & 0.396 & 0.363 & 1.0 & & \\
\hline Non-biophilic & 0.655 & 0.758 & 0.316 & 1.0 & & \\
\hline \multicolumn{7}{|c|}{ Confusion/bewilderment (CB): } \\
\hline Indoor biophilic & 0.316 & 0.199 & 0.276 & 0.302 & 1.0 & \\
\hline Outdoor biophilic & 0.174 & -0.220 & -0.239 & 0.252 & 1.0 & \\
\hline Non-biophilic & 0.182 & 0.196 & 0.301 & 0.190 & 1.0 & \\
\hline \multicolumn{7}{|l|}{ Vigour/activity (VA): } \\
\hline Indoor biophilic & 0.501 & 0.499 & 0.265 & -0.202 & 0.152 & 1.0 \\
\hline Outdoor biophilic & -0.853 & -0.769 & 0.180 & 0.192 & -0.135 & 1.0 \\
\hline Non-biophilic & 0.265 & 0.336 & 0.172 & 0.360 & 0.256 & 1.0 \\
\hline
\end{tabular}

tension (Twohig-Bennett and Jones, 2018). The highest positive correlation was calculated between fatigue and depression mood states of the older adults living in non-biophilic environments. Different than the literature, a medium-positive correlation was found between depression and anxiety in indoor biophilic environments (Yin et al., 2020). The lowest correlation was found between confusion and activity in outdoor biophilic environments. The correlation findings of the study highlight that non-biophilic environments facilitate the highest correlation between depression and anger, while indoor and outdoor biophilic environments facilitate a medium correlation. 


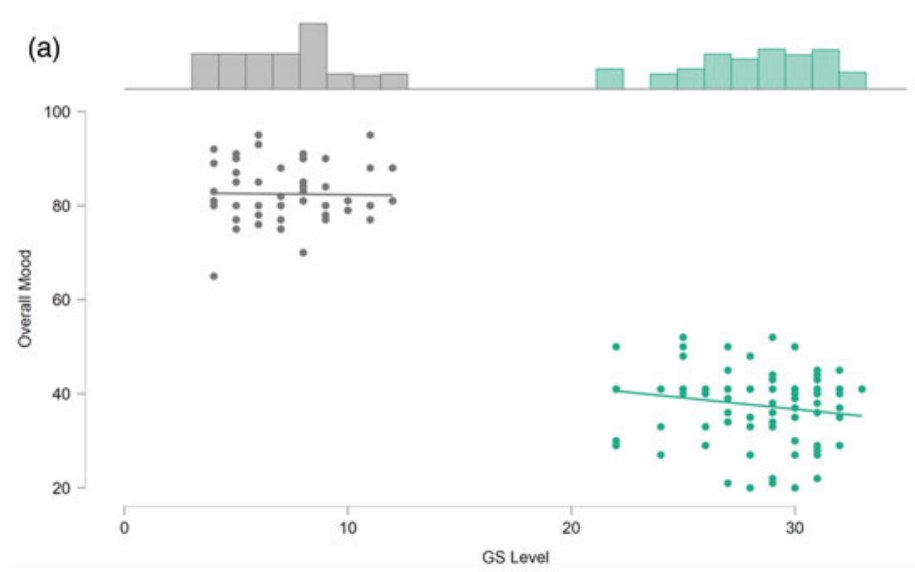

Biophilic Character

(b)

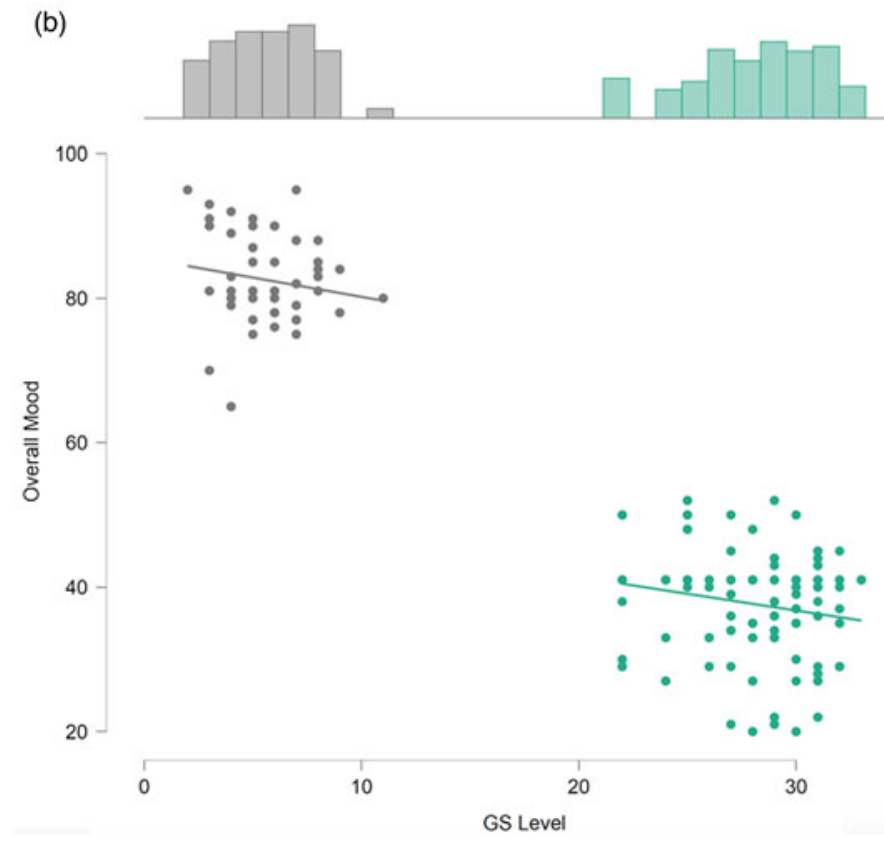

Biophilic Character

- Biophilic

$\rightarrow$ Non-biophilic

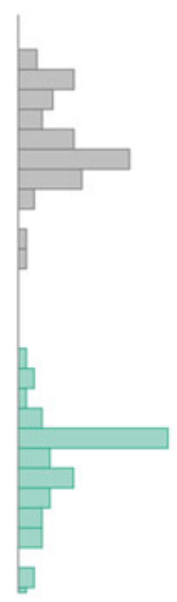

Figure 2. The scatter plot diagram of the relationship between Gerotranscendence Scale (GS) level and overall mood states moderated by the biophilic character: (a) before the COVID-19 pandemic and (b) during the COVID-19 pandemic. The line indicating the relation between overall mood and GS level has a different angle for biophilic environments than for non-biophilic environments, and also before the COVID-19 pandemic than during the pandemic. Specifically, the line is almost flat for non-biophilic environments before the COVID-19 pandemic, indicating that GS level to non-biophilic environments has a very small effect on the overall mood.

The study also analysed the moderator role of the biophilic design on the effect of GS level on the overall mood states. Moderation analysis in JASP was used to test hypotheses $\mathrm{H} 3$ and $\mathrm{H} 4$. Scatter plots in Figure 2 indicate that the effect of the GS level on the overall mood states significantly depends on the biophilic character of 


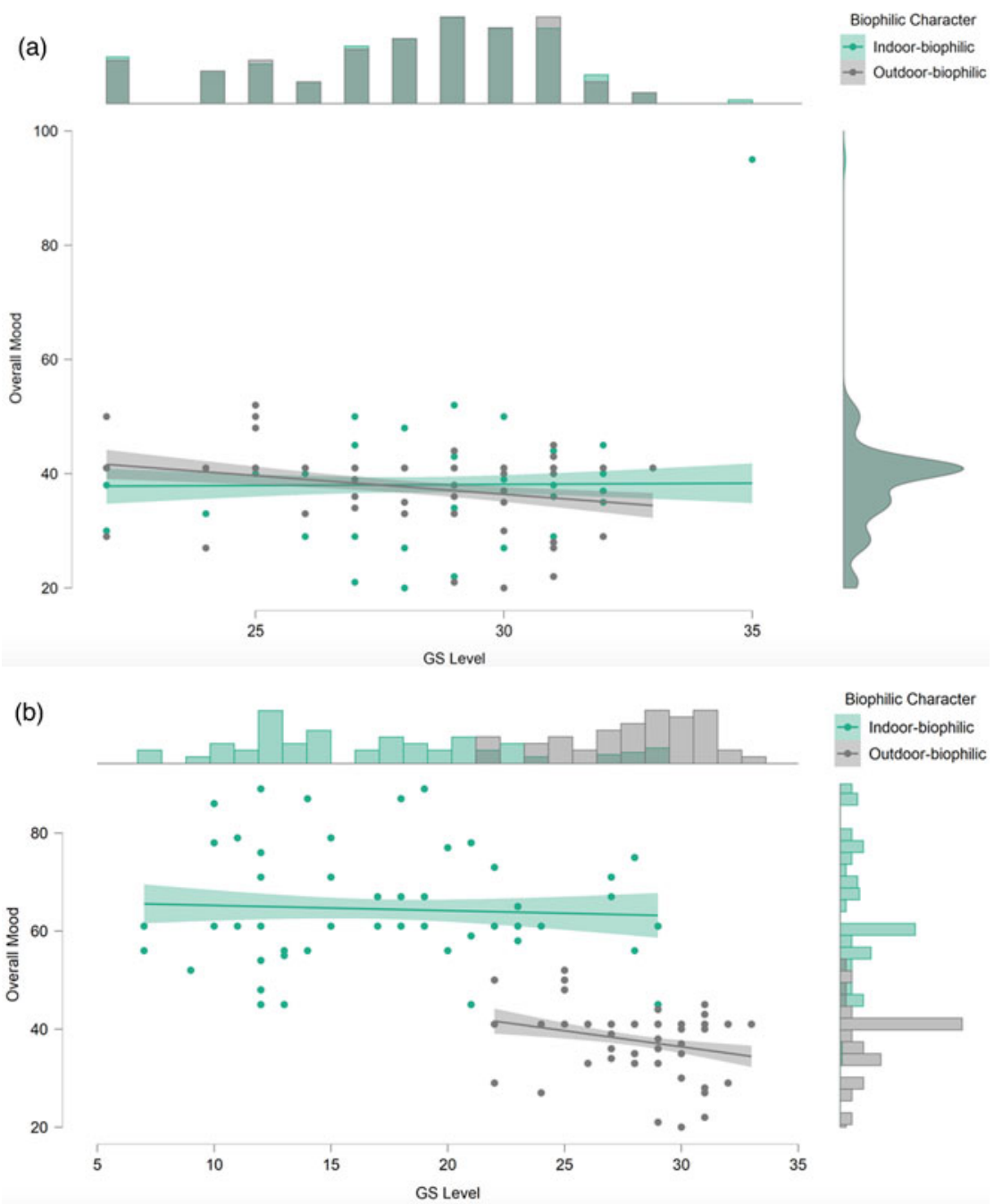

Figure 3. The scatter plot diagram of the relationship between Gerotranscendence Scale (GS) level and overall mood states moderated by the type of biophilic design: (a) before the COVID-19 pandemic and (b) during the COVID-19 pandemic. The line indicating the relation between overall mood and GS level has a different angle for indoor biophilic environments than for outdoor biophilic environments. Specifically, the line is almost flat for indoor biophlic environments compared to outdoor biophilic environments, indicating that GS level to indoor biophilic environments has a very small effect on the overall mood. The confidence intervals indicated by the colored shades around the lines.

the home environment as the moderator, both before and during the COVID-19 pandemic. The study conducted a linear regression analysis to analyse this expected moderation statistically. The biophilic design positively moderates the relationship between GS level (regarding the three sub-scales) and the overall mood states, both before and during the COVID-19 pandemic. The estimated coefficients of the 'before the pandemic' set and 'during the pandemic' set are: $R=0.954 ; R^{2}=0.911$; adjusted 
Table 7. A summary table showing the correlation between all the methods used in the study

\begin{tabular}{|c|c|c|c|c|}
\hline Methods & Major focus & $\begin{array}{l}\text { Hypotheses } \\
\text { number }\end{array}$ & $\begin{array}{l}\text { Hypotheses } \\
\text { status }\end{array}$ & Analysis; output \\
\hline \multirow[t]{2}{*}{$\begin{array}{l}\text { SV-POMS - } 37 \text { items } \\
\text { based on a five-point } \\
\text { Likert scale }\end{array}$} & \multirow{2}{*}{$\begin{array}{l}\text { To explore the extent to which the } \\
\text { participants were experiencing or had } \\
\text { experienced these } 37 \text { mood states in } \\
\text { the past week }\end{array}$} & \multirow[t]{2}{*}{$\mathrm{H} 1$} & \multirow[t]{2}{*}{ Supported } & $\begin{array}{l}\text { ANOVA; significant stress level difference between } \\
\text { indoor biophilic (mean age }=74.5 \text { ) and } \\
\text { non-biophilic environments (mean age }=77.8 \text { ) }\end{array}$ \\
\hline & & & & $\begin{array}{l}\text { Wilcoxon rank; significant increase in the tension } \\
\text { and depression mood states of the participants in } \\
\text { non-biophilic environments (mean age }=77.8 \text { ) } \\
\text { while experiencing the COVID-19 pandemic }\end{array}$ \\
\hline $\begin{array}{l}\text { GS - ten items based } \\
\text { on a five-point Likert } \\
\text { scale }\end{array}$ & & $\mathrm{H} 2$ & $\begin{array}{l}\text { Not } \\
\text { supported }\end{array}$ & $\begin{array}{l}t \text {-Test, ANOVA; the coherence and solitude aspects } \\
\text { as the only dimensions of the GS scale affected by } \\
\text { the pandemic in indoor biophilic (mean age = } \\
74.5 \text { ), outdoor biophilic (mean age }=79.3 \text { ) and } \\
\text { non-biophilic environments (mean age }=77.8 \text { ) }\end{array}$ \\
\hline \multirow[t]{2}{*}{ SV-POMS $\times$ GS } & & $\mathrm{H} 3$ & Supported & \multirow{2}{*}{$\begin{array}{l}\text { Moderation analysis, linear regression analysis; } \\
\text { the biophilic design as the positive moderator of } \\
\text { the relationship between GS level (regarding the } \\
\text { three sub-scales) and the overall mood states }\end{array}$} \\
\hline & & $\mathrm{H} 4$ & Supported & \\
\hline
\end{tabular}

Notes: SV-POMS: shortened version of the Profile of Mood States. GS: Gerotranscendence Scale. ANOVA: analysis of variance. 
$R^{2}=0.910$, Root Mean Square Error of Approximation $($ RMSEA $)=6.630 ; F=$ $2,277.30 ; p<0.001$ and $R=0.972 ; R^{2}=0.945$; adjusted $R^{2}=0.945$, RMSEA $=2.452$; $F=3,835.61 ; p<0.001$, respectively. The study further elaborated this moderation analysis by exploring whether the effect of GS scale on the overall mood states changed based on the type of biophilic characteristics. Biophilic design type as the demographic variable of the participants was added to the linear regression model to control its effect on GS scale and overall mood states. The findings in Figure 3 indicate that the effect of the GS level on the overall mood states does not significantly depend on the biophilic character type of the home environment as the moderator $(p=0.158)$, whereas the outdoor biophilic environment exerted a moderating effect on this relationship during the COVID-19 pandemic. The estimated coefficients of the 'before the pandemic' set and 'during the pandemic' set are: $R=0.111 ; R^{2}=0.012$; adjusted $R^{2}=0.006$, RMSEA $=2.888 ; F=1,858 ; p=0.158$ and $R=0.768 ; R^{2}=0.590 ;$ adjusted $R^{2}=0.588$, RMSEA $=4.623 ; F=214.67 ; p<0.001$, respectively. Table 7 is a summary table showing the correlation between all the methods used in the study. The variable age is included in the output column.

\section{Discussion}

\section{Effects of biophilic design on gerotranscendence and mood states in experiencing the COVID-19 pandemic}

Overall, the findings from the study highlight the significance of biophilic design on positive ageing and an increase in life satisfaction. Participants in non-biophilic environments during the COVID-19 period had greater decreases in the cosmic aspect of the GS scale specifically. This implies that the cosmic dimension of being part of the spirit of the universe as well as the dimension of self, social and personal relationships could be met by nature integration to cope with the negative impacts of the COVID-19 pandemic. This finding was in line with the previous studies highlighting the restorative benefits of natural environments in terms of increased social and psychological wellbeing (Hartig, 2004). Compared with the mood state change in depression and activity in the non-biophilic sample group, the change in depression and activity in the indoor and outdoor biophilic groups was statistically significant. This finding illustrates that the subjective ageing experience of older adults could be enhanced through mood enhancement (Washburn and Williams, 2020). In the study, nature was considered a possible mechanism for positive mood states. Moreover, the findings of the study on sleep quality and stress level are in accordance with the literature (Brown et al., 2013). In the outdoor biophilic group, visual connection with nature helped with stress reduction more compared with the indoor biophilic and non-biophilic groups. These results indicate that outdoor biophilic features facilitate recovery from tension mood effects of the COVID-19 pandemic, whereas indoor biophilic features facilitate recovery from depression and anger. This finding differs from the literature, showing the effect of the pandemic on the relationship between biophilic design and mood states (Yin et al., 2020). Moreover, this study found that fatigue and confusion were the mood states most related to the changing circumstances, regardless of the biophilic character of the living environment. 
The challenges associated with subjective ageing, biophilic design and mood states in changing circumstances

Maintenance of subjective wellbeing in later adulthood is of increasing concern. As noted by Jović and Mitić (2020), bringing nature to living environments is essential to promote social interaction, physical fitness, and emotional health and wellness, while ensuring a sustainable urban experience. This could be achieved by sustainable housing policies, changes in urban development patterns and physical infrastructure design, rather than adding minor nature forms, colours and plants to existing residential buildings. Equally important is establishing continuous contact with nature. This was evident in the participants living in non-biophilic environments who were more tense and unhappy during the COVID-19 pandemic compared with participants living in indoor and outdoor biophilic environments. Although the non-biophilic sample group had the opportunity to contact with nature directly through neighbourhood parks, the recovery effect of this type of contact was not the same as the biophilic character of the living environment.

The study found that the most critical challenge associated with subjective ageing, biophilic design and mood states in changing circumstances was the question of how to cope with the social withdrawal of older adults. In this respect, the coherence and solitude dimensions of gerotranscendence are the most significant dimensions; they were affected significantly by the biophilic character of the environment in this study. However, with regards to the overall GS value, the challenge was not valid because the overall GS ratings of participants living in outdoor biophilic environments remained the same before and during the COVID-19 pandemic. Therefore, understanding the association among gerotranscendence, mood states and biophilic character of living space requires a broader perspective that should go beyond subjective ageing experiences. Personality type, age span and culture are other critical parameters of this association, as suggested by Jewell and Nell (2014).

\section{Conclusion}

This study found that the biophilic characteristics of home environments correlate both positively and negatively with older adults' experience of the multiple levels of the theory of gerotranscendence. The relationship between these experiences and the mood states of these older adults was found to be dynamic depending on the changing circumstances, which, in this study, were based on the comparative analysis of the impact of the COVID-19 pandemic. This comparison would lead to a more comprehensive understanding of the correlation between the ageing experience and built environments. Since the COVID-19 pandemic was unexpected for most people, this sudden pandemic has created negative mood states and affected the experienced positive meaning of life regardless of the design characteristics of people's living environments. Moreover, it is worth noting that this study demonstrates the importance of outdoor biophilic environments in maintaining positive ageing experiences with reduced tension moods during a pandemic. Therefore, this study has the potential to consider the diverse dimensions of gerotranscendence in relation to which older adults are responding to changing mood states, and diverse strategies for developing biophilic age-friendly built environments 
that impact and heal the ageing experience of older adults. Although current policies in Turkey promote healthy ageing and sustainable development, these approaches are very local and the dimensions of gerotranscendence are not perceived as significant to cope with the negative effects of the COVID-19 pandemic; rather, they are limited by the engagement level of both older adults and designers. This study has the following limitations. First, it was conducted in the Turkish culture. The results could be different in a different culture. Second, the study considers participants living in cities. Older adults living in suburban areas and other rural communities could have different mood states and experience ageing differently. Third, the study was based on quantitative findings, which could result in a common method bias. Including qualitative research methods, developing new psychometric measures and/or obtaining data from secondary sources, such as health reports of older adults, would avoid this common method bias.

Notwithstanding these limitations, this study empirically and theoretically contributes to the significance of further studies by elaborating the results in terms of the relationship between ageism and social isolation. Although the participants were recruited from locations determined to have levels of biophilic features, with regards to studies in environmental gerontology there are also important issues to consider outside appearance, such as environmental press, competency, agency and even choice of living location. Regarding positive ageing, there needs to be much greater exploration into the multiple components that influence 'home' and 'place' outside architectural features and/or green space, especially with regards to a concept such as gerotranscendence, which Erikson (1950) placed above wisdom. Future studies could also focus on care homes, where older adults experience ageing with decreased dimensions of personal and social relationships. Moreover, investigating biophilic impacts on the mood states of older adults based on their age (such as those from 65 to 74 years old as early elderly and those over 75 years old as late elderly) would give deeper insights into multiple levels of gerotranscendence. Another potential future study could examine the relationships between the biophilic design preference of older adults and their social connectedness through in-depth interviews.

Supplementary material. The supplementary material for this article can be found at https://doi.org/10. 1017/S0144686X21001860.

Financial support. This work was supported by the grant of the Science Academy's Young Scientist Awards Program 2017 (BAGEP), Turkey.

Conflict of interest. The authors declare no conflicts of interest.

Ethical standards. Ethical permission for the study was obtained first by the Ankara Governorship and then later by the Bilkent University Institutional Ethical Review Board.

\section{References}

Alexopoulos GS, Abrams RC, Young RC and Shamoian CA (1988) Cornell Scale for Depression in Dementia. Biological Psychiatry 23, 271-284.

Barton J and Pretty J (2010) What is the best dose of nature and green exercise for improving mental health? A multi-study analysis. Environmental Science and Technology 44, 3947-3955.

Bauger L and Bongaardt R (2016) The lived experience of well-being in retirement: a phenomenological study. International Journal of Qualitative Studies on Health and Well-being 11, 33110-33121. 
Berto R (2014) The role of nature in coping with psycho-physiological stress: a literature review on restorativeness. Behavioral Sciences 4, 394-409.

Brown DR, Wang Y, Ward A, Ebbeling CB, Fortlage L, Puleo E, Benson H and Rippe JM (1995) Chronic psychological effects of exercise and exercise plus cognitive strategies. Medicine and Science in Sports and Exercise 27, 765-775.

Brown DK, Barton JL and Gladwell VF (2013) Viewing nature scenes positively affects recovery of autonomic function following acute-mental stress. Environmental Science and Technology 47, 5562-5569.

Browning W, Ryan C and Clancy J (2014) 14 Patterns of Biophilic Design. New York: Terrapin Bright Green, LLC.

Calasanti T and King N (2021) Beyond successful aging 2.0: inequalities, ageism, and the ease for normalizing old ages. Journals of Gerontology: Psychological Sciences and Social Sciences 76B, 1817-1827.

Chee SY (2020) COVID-19 pandemic: the lived experiences of older adults in aged care homes. Millennial Asia 11, 299-317.

Chen S, Moyle W and Jones C (2019) Feasibility and effect of a multidimensional support program to improve gerotranscendence perception and depression for older adults: a pragmatic cluster-randomized control study. Research in Gerontological Nursing 12, 148-158.

Clark CM, Lawlor-Savage L and Goghari VM (2017) Functional brain activation associated with working memory training and transfer. Behavioral Brain Research 334, 34-49.

Council of Europe (2021) UN Agenda 2030: The Agenda 2030 for Sustainable Development. Available at https://www.coe.int/en/web/programmes/un-2030-agenda (accessed September 2021).

Dennis M, Ferguson B and Tyrer P (1995) Rating instruments. In Freeman C and Tyrer P (eds), Research Methods in Psychiatry: A Beginner's Guide, 2nd Edn. London: Royal College of Psychiatrists, pp. 98-134.

Denollet J (1993) Emotional distress and fatigue in coronary heart disease: the Global Mood Scale (GMS). Psychological Medicine 23, 111-121.

Diehl MK and Wahl HW (2010) Awareness of age-related change: examination of a (mostly) unexplored concept. Journals of Gerontology: Psychological Sciences and Social Sciences 65B, 340-350.

Ehni H and Wahl HW (2020) Six propositions against ageism in the COVID-19 pandemic. Journal of Aging and Social Policy 32, 515-525.

Erikson EH (1950) Childhood and Society. New York, NY: W.W. Norton and Company.

Erikson EH (1963) Childhood and Society, 2nd Edn. New York, NY: W.W. Norton and Company.

Erikson EH (1982) The Life Cycle Completed. New York, NY: W.W. Norton and Company.

Gomes-Osman J, Cabral DF, Morris TP, McInerney K, Cahalin LP, Rundek T, Oliveira A and Pascual-Leone A (2018) Exercise for cognitive brain health in aging: a systematic review for an evaluation of dose. Neurology: Clinical Practice 8, 257-265.

Grinde B and Patil GG (2009) Biophilia: does visual contact with nature impact on health and well-being? International Journal of Environmental Research and Public Health 6, 2332-2343.

Harper S (2014) Economic and social implications of aging societies. Science 346, 587-591.

Hartig T (2004) Restorative environments. In Spielberger C (ed.), Encyclopedia of Applied Psychology. San Diego: Academic Press, pp. 273-279.

Heerwagen JH and Gregory B (2011) Biophilia and sensory aesthetics. In Kellert SR, Heerwagen J and Mador M (eds), Biophilic Design: The Theory, Science and Practice of Bringing Buildings to Life. Hoboken, NJ: John Wiley and Sons, pp. 227-241.

Heucert JP and McNair DM (2012) POMS 2: Profile of Mood States, 2nd Edn. New York, NY: Multi-Health Systems .

JASP (2021) A Fresh Way to Do Statistics. Available at https://jasp-stats.org.

Jewell A and Nell E (2014) Gerotranscendence. Rural Theology 12, 96-105.

Jin P (1992) Efficacy of Tai Chi, brisk walking, meditation, and reading in reducing mental and emotional stress. Journal of Psychosomatic Research 36, 361-370.

Jothikaran TA, Meershoek A, Ashok L and Krumeich A (2020) Older adults in traditional and modern living arrangements in southern India: the importance of maintaining a sense of belonging and positive intergenerational exchanges. Journal of Aging Studies 54, Article 100867.

Jović BS and Mitić AD (2020) Exploration of nature-based biomimetic approach in landscape architectural design: parametric study of candelabra model design. Visual Computing for Industry, Biomedicine, and Art 3, Article 25. 
Kaplan R and Kaplan S (1989) The Experience of Nature: A Psychological Perspective. Cambridge: Cambridge University Press.

Kellert SR and Wilson EO (1993) The Biophilia Hypothesis. Washington, DC: Island Press.

Kellert SR, Heerwagen JH and Mador ML (eds) (2008) Biophilic Design: The Theory, Science and Practice of Bringing Buildings to Life. Hoboken, NJ: John Wiley and Sons.

Klepeis NE, Nelson WC, Ott WR, Robinson JP, Tsang AM, Switzer PB, Joseph V, Hern SC and Engelmann WH (2001) The National Human Activity Pattern Survey (NHAPS): a resource for assessing exposure to environmental pollutants. Journal of Exposure Analysis and Environmental Epidemiology 11, 231-252.

Kunzmann U, Little TD and Smith J (2000) Is age-related stability of subjective well-being a paradox? Crosssectional and longitudinal evidence from the Berlin Aging Study. Psychology and Aging 15, 511-526.

Lai MM, Lein SY, Lau SH and Lai ML (2016) Modeling age-friendly environment, active aging, and social connectedness in an emerging Asian economy. Journal of Aging Research 4, 1-14.

Mahoney FI and Barthel DW (1965) A Simple Index of Independence Useful in Scoring Improvement in the Rehabilitation of the Chronically Ill. Baltimore, MD: Rehabilitation Section Baltimore City Medical Society.

McNair DM, Lorr M and Droppelman L (1971) Manual: Profile of Mood States. San Diego, CA: Educational and Industrial Testing Service.

Parsaee M, Demers CMH, Hébert M, Lalonde JF and Potvin A (2019) A photobiological approach to biophilic design in extreme climates. Building and Environment 154, 211-226.

Patton JF (2006) Jungian spirituality: a developmental context for late life growth. American Journal of Hospice and Palliative Medicine 23, 304-308.

Piccirilli M, Pigliautile M, Arcelli P, Baratta I and Ferretti S (2019) Improvement in cognitive performance and mood in healthy older adults: a multimodal approach. European Journal of Ageing 16, 327-336.

Podsakoff PM and Organ DW (1986) Self-reports in organizational research: problems and prospects. Journal of Management 12, 531-544.

Radloff LS (1977) The CES-D scale: a self-report depression scale for research in the general population. Applied Psychological Measurement 1, 385-401.

Ratan A and de Vries K (2020) 'Just another day': the lived experience of being a hundred years old for ten New Zealanders. Ageing \& Society 40, 1387-1404.

Rodrigues LM (2016) The Meaning of a Visual Arts Program for Older Adults in Long Term Care (Unpublished master's thesis). University of Victoria, Victoria, Canada.

Rowe JW and Kahn RL (2015) Successful aging 2.0: conceptual expansions for the 21st century. Journals of Gerontology Series B: Psychological Sciences and Social Sciences 70B, 593-596.

Salingaros NA (2006) A Theory of Architecture. Portland, OR: Sustasis Press.

Salingaros NA (2015) Biophilia and Healing Environments. New York, NY and Amherst, MA: Terrapin Bright Green and Levellers Press.

Salingaros N (2019) The biophilic healing index predicts effects of the built environment on our wellbeing. Journal of Biourbanism 8, 13-14.

Selvi Y, Gulec M, Aydın A and Beşiroğlu L (2011) Psychometric evaluation of the Turkish language version of the Profile of Mood States (POMS). Journal of Mood Disorders 1, 152-161.

Shacham S (1983) A shortened version of the Profile of Mood States. Journal of Personality Assessment 7, 305-306.

Spielberger CD (1983) Manual for the State-Trait Anxiety Inventory: STAI. Palo Alto, CA: Consulting Psychologists Press.

Substance Abuse and Mental Health Services Administration (2018) Key Substance Use and Mental Health Indicators in the United States: Results from the 2017 National Survey on Drug Use and Health (HHS Publication No. SMA 18-5068, NSDUH Series H-53). Rockville, MD: Center for Behavioral Health Statistics and Quality.

Sunderland T, Alterman IS, Yount D, Hill JL, Tariot PN, Newhouse PA, Mueller EA, Mellow AM and Cohen RM (1988) A new scale for the assessment of depressed mood in demented patients. American Journal of Psychiatry 145, 955-959.

Tesch-Römer C and Wahl HW (2017) Successful aging and aging with care needs: arguments for a comprehensive concept of successful aging. Journals of Gerontology: Psychological Sciences and Social Sciences 72B, 310-318. 
Tornstam L (1989) Gero-transcendence: a reformulation of the disengagement theory. Aging 1, 55-63.

Tornstam L (1994) Gerotranscendence: a theoretical and empirical exploration. In Thomas LE and Eisenhandler SA (eds), Aging and the Religious Dimension. Westport, CT: Greenwood, pp. 203-225.

Tornstam L (1997) Gerotranscendence: the contemplative dimension of aging. Journal of Aging Studies 11, $143-154$.

Tornstam L (2005) Gerotranscendence: A Developmental Theory of Positive Aging. New York, NY: Springer.

Tornstam L (2011) Maturing into gerotranscendence. Journal of Transpersonal Psychology 43, 166-180.

Turkstat (2019) Istatistiklerle yaşllar. Available at http://www.tuik.gov.tr/PreHaberBultenleri.do?id=33712.

Twohig-Bennett $\mathbf{C}$ and Jones A (2018) The health benefits of the great outdoors: a systematic review and meta-analysis of greenspace exposure and health outcomes. Environmental Research 166, 628-637.

Ulrich RS, Simons RF, Losito BD, Fiorito E, Miles MA and Zelson M (1991) Stress recovery during exposure to natural and urban environments. Journal of Environmental Psychology 11, 201-230.

Van den Berg AE, Hartig T and Staats H (2007) Preference for nature in urbanized societies: stress, restoration, and the pursuit of sustainability. Journal of Social Issues 63, 79-96.

Washburn AM and Williams S (2020) Becoming and being an older adult: a mixed methods study of the lived experience of aging. Journal of Aging Studies 54, Article 100871.

Watson D (2000) Mood and Temperament. New York, NY: Guilford Press.

Watson D, Clark LA and Tellegen A (1988) Development and validation of brief measures of positive and negative affect: the PANAS scales. Journal of Personality and Social Psychology 54, 1063-1070.

Wilson EO (1984) Biophilia. Cambridge, MA: Harvard University Press.

World Health Organization (2013) Mental Health Action Plan 2013-2020. Geneva: World Health Organization.

Yesavage JA, Brink TL, Rose TL, Lum O, Huang V, Adey M and Leirer VO (1983) Development and validation of a geriatric depression screening scale: a preliminary report. Journal of Psychiatric Research 17, 37-49.

Yin J, Yuan J, Arfaei N, Catalano PJ, Allen JG and Spengler JD (2020) Effects of biophilic indoor environment on stress and anxiety recovery: a between-subjects experiment in virtual reality. Environment International 136, 105427.

Yue X, Vessel EA and Biederman I (2006) The neural basis of preference for natural scenes. Journal of Vision 6, 474-474a.

Zung WWK (1965) A self-rating depression scale. Archives of General Psychiatry 12, 63-70.

Cite this article: Afacan Y (2021). Impacts of biophilic design on the development of gerotranscendence and the Profile of Mood States during the COVID-19 pandemic. Ageing \& Society 1-25. https://doi.org/ $10.1017 / \mathrm{S} 0144686 \mathrm{X} 21001860$ 